\title{
Features of music perception by persons with addictive behaviour
}

\begin{abstract}
Introduction. Early detection of the person's mental dependence on psychotropic substances enables timely correction of deviations in his/her behavior. Given the symptom of the anosognosy, the search for projective methods for determining the presence of mental dependence is required. Certain personality features that determine dependence can be reflected in the perception of music.

Aim. The goal of the research was to determine the connecting features of the perception of music with the presence of the person's mental dependence on psychotropic substances.

Material and methods. The study involved students aged 18-19. There were 50 students in the standard group. The experimental group consisted of another 50 students with addictive behavior. They were of the same age and were patients in the centers of medical and social rehabilitation. For the study of personal qualities, the following methods were applied: the method of determining the level of subjective control by J. Rotter, the method of narrative by N. Chepeleva, the frustration test by Rosenzweig and six specially created musical fragments which represented a certain musical discourse.

Results. An analysis of the selection of the musical fragments by students and individuals with addictive behavior has shown that there are statistically significant differences. Students, in comparison with those with addictive behavior, have mature social concept of "I-concept", and this fact underlies the fact that they give the highest ratings to classical music. An empirical study has shown the connection between the the first stage selection of musical fragments that have certain psychological content and the presence of dependence on psychotropic substances.

Conclusions. Musical discourse, due to the specific influence on the emotional sphere of a person, causes a certain response, relevant to its personality properties. The connection of psychological peculiarities of persons with addictive behavior and their perception of music is established: their emotional mood corresponds to music of a destructive character, which symbolizes aggression and has a dangerous influence on the mental state of a person. We defined musical discourses, the content of which can serve as stimulating material for determining certain personal characteristics that indicate the dependence on psychotropic substances.
\end{abstract}

Keywords: addictive behaviour, musical discourse, personality, maladjustment, projective methods.

DOI: $10.1515 /$ pjph-2017-0016

\section{INTRODUCTION}

It is known that persons with addictive behaviour almost never seek help at the first stage of the disease. Psychological dependency on psychotropic substances is not perceived by them as a disease. They visit a doctor only at the stage of physical dependence, which greatly complicates their medical and social rehabilitation. This situation can be helped with the "crisis intervention" techniques. However, the effectiveness of such interventions is problematic without a reliable diagnosis of the first stage of addictive behaviour. This problem becomes more complex because persons with addictive behaviour, due to anosognosia, refuse to undergo medical and psychological examination to determine a degree of their addiction. Dependence on psychotropic substances and other addictions are always associated with distortions in personal socialization. Consequently, there are certain personal peculiarities that can become "markers" for existence of the first stage of addictive behaviour. The early detection of the person's psychological dependence on psychotropic substances allows psychologists to timely correct deviations in his/her behaviour. Therefore, the subject of our study is to discover how personal traits can be reflected in perception of music, and thus become a starting point for diagnosing of the first stage addiction.

Considering the special role of unconscious processes in emotional sphere functioning during addiction progression, we have assumed that peculiarities of music perception are one of the parameters helping to determine psychological dependence on psychotropic substances.

A person's musical interests form one of the parts of his/ her universal spiritual culture, and here, as in the mirror, his/her whole personality with all his/her traits can be reflected with greater or less fullness. In our opinion, the mechanism of music influence on a person can be represented in such a way: 
affects, caused by music and experienced by a person with all their reality and strength, are the basis of an aesthetic reaction and these affects are eased in fantasy. Due to this, external motor reactions on affects are delayed and suppressed, and the person experiences a feeling that reflects his/her inner world.

\section{AIM}

The research goal was to determine correlations between features of music perception and existence of a person's psychological dependence on psychotropic substances.

\section{MATERIAL AND METHODS}

\section{Theoretical foundations}

The examined literature sources show [1-3] that determining correlations between peculiarities of music perception and personal traits is extremely important. We should emphasize the necessity to take into account a person's subjective activities based on his/her personal traits and creating a new integral system of mental images, much more comprehensive than musical sounds.

According to V. I. Petrushin [4], the high appreciation and recognition of classical music as an important element of psychological well-being appears at a person as a result of a certain maturity of his/her pro-social attitudes, his/her choice of lifestyle determined by the system of positive personal values and his/her self-concept in general. Absence of such personal traits not only reduces the person's social adaptability, but also can lead to reducing of mental health, what further leads to social maladjustment [5]. Persons with addictive behaviour are characterized by personal disharmony, whereas people with stable and balanced psyche have certain positive personal traits: developed reflection and capability to integrate their life experiences, the internal locus of control and their constructive behaviour in frustrating situations.

Modern studies [2,6] of musical influence on a person prove that music, by causing opposite directed affects, delays (only due to the antithesis beginning) a motor emotional reaction by pushing into opposing pulses, destroys the affects of the content and of a form, and leads to an explosion, as well as to easing of nervous energy. This transformation of affects, their self-burning, an explosive reaction leading to easing of induced at this very moment emotions create the catharsis of an aesthetic reaction.

\section{Research method and the sample}

We have chosen people with different (contrasting) sociopsychological characteristics to study the peculiarities of music perception. The control group included students aged 1819 years old, who, according to the experts, were personally mature, studied well and lived in a favourable social situation. This group included 50 students of $3 \mathrm{rd}$ and 4 th years of studies at different faculties of the Taras Shevchenko National University of Kyiv and the Kyiv National University of Technology and Design. The experimental group consisted of 18-19 years old persons with addictive behaviour (namely, first stage drug addicts) form the centres of medical and social rehabilitation. The group consisted of 50 people.

\section{Questionnaire description}

An integrated approach was implemented in the research that included a set of empirical techniques and the methods of mathematical statistics. We used the following techniques of personal trait research: J. Rotter's method determining locus of subjective control [7], N.V.Chepelyeva's techniques of narrative [8], the Rosenzweig Picture Frustration Test [9].

In accordance with the research goal, we tried to identify relations between emotional experiences caused by listening to musical pieces representing a certain musical discourse, and such personal traits that hinder a person's successful social adaptation. Such discursive approach to research on the role of music in studying personality, gives the opportunity to go beyond the purely musical examination of musical pieces. In order to determine the influence of personal traits on a person's musical perception, it is necessary to develop and introduce the categorical apparatus of the "musical discourse" concept as a basic component of a musical and communicative act. Based on the defined "musical discourse" concept, we have developed stimuli for studying music perception peculiarities. We tried to find out relations between drug addicts' personality traits and their choice of musical pieces having different psychological contents.

Here is a description of the used musical pieces, representing certain musical discourses (it should be noted that the musical fragments were created in accordance with the psychological content of the world perception reflected in music):

I. The "destructive" musical fragment - music with unnatural sounds. This is achieved by the effects of overload, overdrive, fuzz and distortion of the frequency modulation characteristics of sounds. The general characteristic of these effects is creation of "overload" of the audio tract. A repeating rhythmic phrase sounds throughout the entire piece without changes. The tempo is mobile and the melodic line is unclear. Its psychological content is an imitation of destructive or chaotic actions, causing a sense of absorption and desire to recklessly join a bacchanalia.

II. The "harmonious" fragment - music corresponds to the classical features. There is always an interrupted cadence in the middle of a "period" and a full authentic cadence at the end. In the case of tone modulation, a double dominant is used, which was widely used in classical works of the 18th century. The rhythm is simple, while the melody is consonant and balanced. The sound dynamics is contrasting and corresponds to classical musical means. Its psychological content is elegance and perfection of harmony evoking piety before the majesty and beauty of eternal truths.

III. The "amorphous" fragment - its main feature is "fluidity". The musical fragment does not have a clear musical form. Its content is meditative. This is achieved through improvisation and playing on non-tempered modes. Dissonance and consonance understood as tension and release are absent due to the non-tension mode. The tempo is slow or moderate. The rhythm is unstable, its main feature is fluidity, while the melody is practically not traceable. Its dynamics is characterized by homogeneity. The music does not have any clear musical form. According to the psychological content, this music reflects passivity, rejection of a purposeful activity.

IV. The "dramatic" fragment - this music is characterised by combination of many emotional experiences. The constant alternation of major-minor colours revokes emotional strain and sympathy. Its dynamics forms waves and cycles. 
The rhythmic component resembles a wide breath. The tender melody sounds clearly and distinctly. The psychological content of this music reflects dramatic events in human life.

V. The "primitive" fragment - this music has features of folk and pop music. The main meaningful accent is based on a simple motive. The motive uses alternating syncope and direct rhythm. This piece has some features of entertaining music. Its psychological content is the following: the music reflects the character of a person having a frivolous, simplistic approach to life.

VI. The "energetic" fragment - prompting to actions and movements. This fragment has a clear rhythm, fast tempo (125-144 bpm), accents on the first and third rhythmic beat. It is accompanied by a drumming rhythm (sixteenth), adding "flickering" or vibration, which prompts new movements. A simple clear rhythm gives energy. The melody is fast, constantly ascending towards the climax. Its psychological content is the following: the music induces actions and movements.

\section{RESULTS}

The performed analysis of musical fragment selection by the students and the respondents with addictive behaviour has shown that there are statistically significant differences. The students' (the control group's) perception of the psychological content of music is more adequate than that of the drug addicts. It should be noted that, when recognizing the musical perception adequacy, we relied on the coincidence of the respondent's interpretation with the conclusions of experts, which were identified as a benchmark in our previous studies [10].

Students, in comparison with persons having addictive behaviour, have more mature self-concept from the social point of view, and this fact underlies their higher valuation of classical music. The low-end art and, in particular, low-artistic samples of rock music as a kind of psycho-emotional doping are rejected not only by people received good musical education, such education, is of course necessary, but also by people having high self-esteem with formed positive self-concept.

The performed analysis of the musical fragment perception shows that the music pieces, conventionally described as "energetic" and "dramatic", evoke images with negative modalities more often in drug addicts than in the students. For example, when listening to the musical part number 3 ("energetic"), the persons with addictive behaviour mentioned images related to aggression (fights, hunting, battles). It was observed three times more often in them than in the students. The latter ones, when listening to this music, mentioned a picture of tension and dynamism - sports competitions, goal achievement.

Absence of drug addicts' personal maturity also manifested in the fact that, describing the "dramatic" fragment, they gave a small number of responses revealing their desire to find ways out of a difficult life situation. The existing correlation between the onset of drug use and a crisis stage in human life, gives reason to believe that a traumatic situation is a condition for actualization of a person's certain structures that impede his/her normal socialization. In difficult life circumstances, those who are unable to find a constructive way out of a traumatic situation are helpless. If they also do not have any effective mechanisms of psychological protection, they, figuratively speaking, are choked because of negative emotional states.

The study of correlations between musical fragment selection and the addicts' psychological peculiarities has shown these people's drive for dangerous musical environment, namely to such musical patterns that are based on dissonances, include "non-musical" sounds (iron clanking, rumbling of falling water or stones, sounds of electric saws or other technical working devices) and have very high volume. In addition, they like the music of amorphous nature, which has a dangerous effect on people's psychological states (excessive repetitions, having a hypnotic, trance effect).

The performed analysis of the musical fragment choice by the two groups shows a correlation between personality traits and musical preferences. In particular, the respondents positively evaluating the musical part number 3 belong to internals in accordance with the technique determining the locus of subjective control (Spirman coefficient of rank correlation is 0.67 ), while the respondents positively evaluating the music fragment number 1 are externals (Spirman coefficient of rank correlation is 0.71 ). Consequently, persons with the external locus of control, choose musical discourses that, as for their psychological content, reflect uncertainty, amorphism of world perception or its simplicity, primitiveness. On the contrary, persons with the internal locus of control, choose energetic, purposeful music.

The level of reflection development of the respondents from both groups and the degree of their ability to integrate their life experiences was discovered by analyzing their narratives with the appropriate markers. The experimental data presented in Figure 1 confirm that the students have much higher ability to integrate their personal experience than the drug addicted young people.

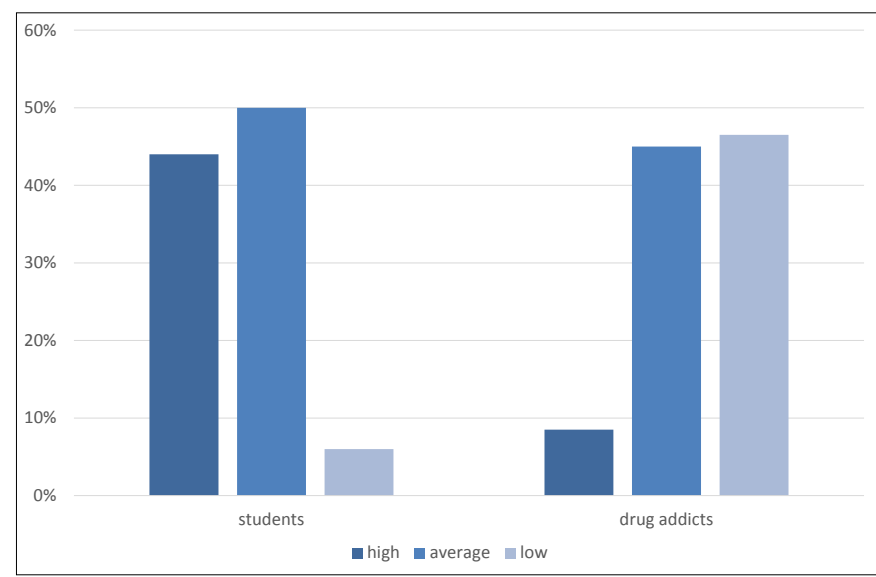

FIGURE 1. Distribution of the respondents in accordance with their reflection development and their ability to integrate their life experiences.

Thus, the respondents with drug addiction have low level of their ability to analyze events taking place in their lives, assess their role in them, their capabilities and abilities, and are not willing to draw conclusions from these events. The reliability of such differences is confirmed by the Wilcoxon-Mann-Whitney criterion $(\mathrm{p}<0.01)$.

Therefore, the performed empirical study has shown the existence of a correlation between the selection of musical fragments that have a certain psychological content and existence of the first stage dependence on psychotropic substances.

Based on the study results, it became possible to develop the diagnostic method for people with predisposition to addictive behaviour. The expediency of a projective technique is determined by its ability to address psychological components at the unconscious level, and to identify personal disharmonies 
of an examined person. Our method development is based on determination of the patterns of musical discourse choice by the respondents. In accordance with the performed correlation analysis, we have identified, from all the variety of possible options of musical fragments choice, certain combinations based on the respondents' contrasting assessments. Therefore, musical discourse has become the constitutive characteristic of the respondents. In addition to choosing a particular pattern of musical discourse, we have also evaluated the respondents' statements as for each fragment. Due to the content analysis, normative statements were defined in a way that were translated into points, which allowed us to provide a generalized assessment of total musical discourse.

The validity of the data obtained by our method of musical fragment selecting was verified by the means of constructive and empirical validity in accordance with the differential psychometric requirements.

Using the results of the psychological diagnostic survey with the abovementioned methods, all the respondents were divided into four groups as for their social adaptability: I - low, II - average, III - high and IV - level of self-actualization.

Detailed results are presented in Figure 2.

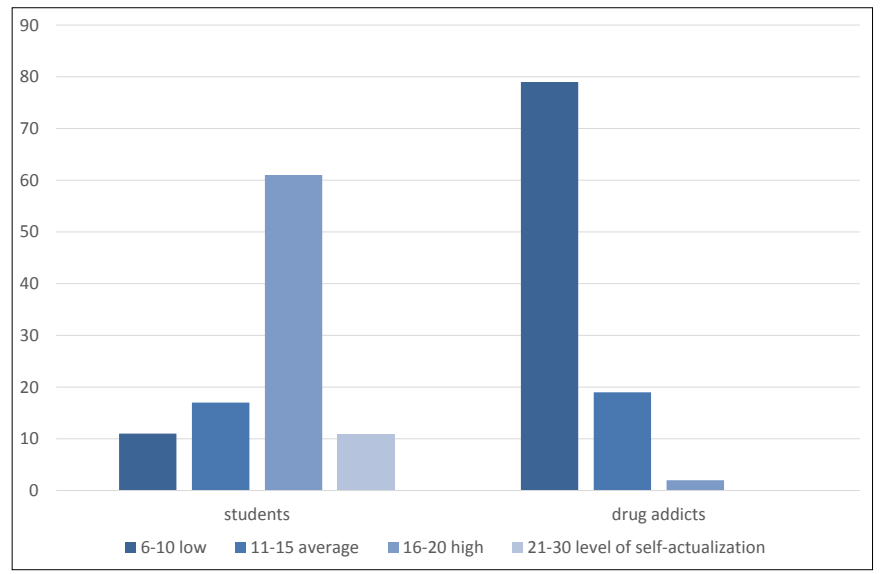

FIGURE 1. Distribution of the respondents in accordance with their reflection development and their ability to integrate their life experiences.

As the diagram shows, persons with addictive behaviour have low level of social adaptation. Consequently, determination of persons who need psychological correction is possible with this method.

\section{CONCLUSION}

1. There are relations of emotional experiences caused by listening to musical fragments, having a certain psychological meaning, with same personal traits hindering successful social adaptation.

2. Musical discourse, due to its specific influence on a person's emotional sphere, causes a certain response that is relevant to the person's traits. The correlation between the psychological properties of people with addictive behaviour and, therefore, with the low level of social adaptation, and peculiarities of their music perception has been established: their emotional mood and the general background of their worldview correspond to the music of destructive nature, symbolizing aggression and having a dangerous influence on their mental states: too loud sounds, unnatural sound- frequency characteristics, excessive repetition, which has a hypnotic, trance effect.

3. We have defined the musical discourses that can serve as stimuli for identifying certain personality traits related to dependence on psychotropic substances.

4. The expediency of the projective method using to identify persons with addictive behaviour is substantiated by the fact that such persons require special means for psychological correction. Only timely provision of social and psychological assistance to these people helps to prevent their advance to the second stage of dependence on psychotropic substances.

\section{REFERENCES}

1. Vygotsky LS. Psychology of Art. In: M.G. Yaroshevsky. Pedagogy; 1987.

2. Hodges D. Handbook of music psychology. Second Edition. Missouri, USA: MMB music; November 1996.

3. Sloboda JA, O'Neill SA. Emotions in everyday listening to music. In P.N. Juslin, J. A. Sloboda (Eds.), Music and Emotion: Theory and Research. Oxford: Oxford University Press;2001. p.415-30.

4. Petrushin VI. The musical psychology. Publishing House: Academic Project ;2008. p. 400.

5. Stetskova O. Socio-psychological rehabilitation of drug users in day-today programs. ICC "Lesta"; 2006.

6. Ponomarenko YG. Musical expression as a subject of perception. Problems of general and pedagogical psychology. $\mathrm{Zb}$ scientific works of the G. S. Kostiuk Institute of Psychology of the Academy of Pedagogical Sciences of Ukraine. S. D.Maksimenko (ed) 2005;VII(2):173-9.

7. Rotter JB. Cognates of personal control: Locus of control, self-efficacy, and explanatory style. Applied and Preventive Psychology, 1992. p.127-9.

8. Chepelya NV. Socio-psychological factors of understanding and interpretation of personal experience: monograph K.: Pedagogical thought; 2008. p. 255

9. Rosenzweig test. Method of drawing frustration (modified by N.V. Tarabrina). Diagnosis of emotional and moral development. SPb; 2002. p.15072.

10. Maximov MV. International Scientific and Practical Conference "Sociology of individuality in the minds of systemic zmin: theoretical and applied problems"; 2009.

Corresponding author

Mykola Maksymov

Department of Developmental Psychology, Faculty of Psychology

E-mail: nmaximov@mail.ru 